\title{
SHAREHOLDING OPERATION OF PRODUCT REMANUFACTURING - FROM A SUSTAINABLE PRODUCTION PERSPECTIVE
}

\author{
Junwu Chai ${ }^{1,2}$, Hengyu Li ${ }^{1, *}$, Chien-Hung LeE ${ }^{3, *}$, Sang-Bing Tsai ${ }^{4, *}$ \\ AND HONG $\mathrm{CHEN}^{1}$
}

\begin{abstract}
We consider a supply chain in which an original equipment manufacturer (OEM) authorizes the remanufacturing business to a third-party remanufacturer (TPR). The OEM may make an investment to hold equity in TPR. This operation not only enables OEM to share the profit of the TPR as a forward shareholding supply chain, but also improve the production efficiency of the TPR and consequently benefits the whole supply chain. We characterize the equilibrium production decisions of all members by using Stackelberg game in such a supply chain. We find that shareholding operation by OEM helps increase the production quantity of remanufactured products and total market volume. From the economic perspective, our results show both sides in the forward shareholding supply chain prefer the shareholding operation if the equity holding cost and remanufactured cost is relatively small. Additionally, from an environmental perspective, our results show under certain relative pollution ratio of remanufactured products, shareholding operation can reduce environmental impact. Finally, we check the key results by stimulating numerical examples and obtain some useful management insights.
\end{abstract}

Mathematics Subject Classification. 90A35, 90B30, 91A10, 91B42.

Received August 11, 2019. Accepted April 28, 2020.

\section{INTRODUCTION}

Developments in science and technology have accelerated the differentiation and renewal of high-tech products and greatly shortened the life cycle of products, resulting in a vast number of discarded or end-of-life (EOL) products [55]. Consequently, this has not only significantly negatively impacted the environment, but has also wasted a lot of valuable resources and energy [58]. In order to alleviate the negative impact of waste products on the environment, governments all over the world are beginning to attach great importance to reusable waste, which reduces resource and energy consumption, and, subsequently, makes use of the surplus value of EOL products [50]. Accordingly, remanufacturing is considered to be one of the most important methods in developing a circular sustainable economy and will continue to play an essential role in the issues surrounding industrial environmental protection increasingly confronting the world [54]. The remanufacturing industry in

Keywords. Sustainable supply chain, forward shareholding, stackelberg game, remanufacturing operation, sustainable production, LCA.

1 School of Management and Economics, University of Electronic Science and Technology of China, Chengdu 611731, P.R. China.

2 Center for West African Studies of University of Electronic Science and Technology of China, Chengdu 611731, P.R. China.

3 College of Tourism and Service Management, Nankai University, Tianjin 300071, P.R. China.

4 Regional Green Economy Development Research Center, School of Business, WUYI University, Wuyishan 354300, P.R. China.

*Corresponding authors: lihengyu@std.uestc.edu.cn (H.L.); sangbing@hotmail.com (S.T.); chateau.frank@gmail.com (C.L.) 
the developed world is growing rapidly, with more than $\$ 140$ billion and directly employed nearly more than five million jobs worldwide. In the USA, remanufacturing output is worth $\$ 75$ billion, and provides 180000 full-time jobs [33].

However, not all OEMs are willing or capable of remanufacturing used products in a profitable manner due to a lack of relevant technologies [32], the unprofitability associated with investing in new infrastructure and training professionals [6], and the damage to the image of the OEM's brand [15]. Consequently, the remanufacturing sector is dominated by third-party remanufacturers (TPRs) in many industries [63]. With the known advantages for environmental protection, as well as the economic benefits associated with remanufacturing, this sector is becoming increasingly recognizable to governments and private enterprises $[9,18]$. Furthermore, the continuous reduction in remanufacturing costs and increases in the quality of remanufactured products results in intense competition between new products from OEMs and the remanufactured products from TPRs [39]. As a result, OEMs have begun to charge a license fee for remanufacturing of products, and this setting may reflect circumstances in which the remanufacturing industry is particularly inefficient, causing a double marginalization problem to arise [49].

As a consequence, firms in the supply chain tend to explore a better way of cooperation to maximize profits. Equity participation of one party with another has been observed widely in industries, and this phenomenon is called the 'partial vertical ownership' (PVO) in the vertical supply chain or 'strategic collaborations' in hightech industries [12]. OEMs expect to enter the remanufacturing business by way of a shareholding operation and to control the production and pricing of remanufactured goods, which may allow the acquirer to play a role in monitoring and disciplining target management. With this type of "collaboration", parties in the supply chain can advocate for a contract to share profits through proportion in equity. Therefore, there is the potential that the PVO may be able to moderate double marginalization due to the promotion of "bonding" between upstream and downstream firms through revenue sharing [23]. For example, PVO is common to the automobile industry - e.g., Toyota shares were held by the manufacturer for General Motors [17].

Besides the automobile industry, this pattern of holding-share is undergoing rapid developments in the remanufacturing sector in China [53]. For example, Cummins Inc. in China has become a shareholder of Navistar in view of the remanufacturing standards in the Chinese market and the needs of consumers in order to meet the stringent emission regulations and, simultaneously, achieve continuous improvement in performance and efficiency. Likewise, Guangxi Yuchai Machinery Co., Ltd. (GYMCL) has taken ownership of the remanufacturing company, Caterpillar China, who provides remanufacturing services for diesel engines and components. Compared with less than $40 \%$ before, GYMCL can achieve a remanufacturing rate of $60-70 \%$. Such mutually beneficial partnership generated $\$ 300$ million in sales and helped GYMCL enter China's top 500 companies' list. Early, Land Rover have signed an agreement about with Caterpillar. Caterpillar was allowed to produce the remanufactured engines qualified by Land Rover and share revenues. These cases demonstrate that "shareholding" in remanufacturing has become the driving force behind OEMs' return to the remanufacturing sector.

Nevertheless, there are both advantages and disadvantages associated with economic performance within the partial ownership strategy. On the one hand, moving forward in an unfamiliar market through investing in equity with other enterprise and obtaining additional profits through profit distribution is relatively effective. On the other hand, such operating shareholding may lead to declines in a positive economic effect overall due to the instability of the alliance and high holding cost of equity. Based on such uncertainty, the main purpose of this paper is to explore whether "shareholding" as business cooperation is beneficial to the OEM, TPR or detrimental to the them from a sustainable production perspective. In particular, we aim to answer the following questions:

(1) What are the optimal decision-making adjustments of OEM and TPR with the shareholding business?

(2) Whether equity participation achieves benefits for all parties in the supply chain?

(3) What is the environmental impact of the OEM's shareholding operation on TPR's remanufacturing?

(4) Under what conditions an economic and environmental win-win situation can be achieved in terms of shareholding operation? 
In order to approach a better understanding of the abovementioned questions, this investigation utilized a Stackelberg game model with an OEM in a leadership position and a TPR as follower. The Stackelberg model is a strategic game in economics in which the leader firm moves first and then the follower firms move sequentially $[15,44,57]$. Here, Stackelberg game model reflected the fact that OEM usually have pricing right of license fee, bargaining power and the ability to choose whether or not buy into TPR's share. We proposed two types of exclusive authority to TPR, including a license fee operation (Model $N$ ) and a shareholding operation (Model $S$ ). Under these two operations, the OEM and TPR developed competition in the terminal market through new and remanufactured products. Through solving the equilibrium solution for the OEM and TPR under two operations, the effectiveness boundary for the remanufacturing sector for the TPR and that of the shareholding operation for the OEM is found. Moreover, in some situations we found the shareholding operation to be of benefit to the whole supply chain. From an environmental perspective, we determined the scope of the remanufactured cost and environmental coefficient, which achieved a win-win situation for both the manufacturing economy and the environment. Essentially, Model $N$ always had a smaller consumer surplus compared with Model $S$. More specifically, apart from regular profitability, we compared the social benefits of both models and found that, when the environmental impact generated by remanufactured products is small and the holding cost of equity were not too pronounced, the shareholding operation had significant social benefits on consumer surplus, economy and environment impacts.

The remainder of this paper is organized as follows: Section 2 reviews the relevant literature and explains our contributions in more detail; Section 3 describes the research hypotheses and the model symbols; Section 4 builds and solves mathematical models for two different operations; Section 5 analyzes their optimal decisions and presents the main results from the production decision-making, economic and environmental benefits; Section 6 gives some more intuitive numerical examples; and, finally, Section 7 provides our concluding remarks and presents suggestions for future research directions. All evidence for this study is presented in the Appendix A.

\section{Literature REVIEW}

The paper is related to the literature on competition between OEM and TPR, product life cycle and forward shareholding.

In general, competition between the OEM and the TPR has become an inevitable trend in the development of the remanufacturing sector. The body of literature on remanufacturing has been expanding. Following extensive economics literature, most research assumes that the consumers typically value less on remanufactured products to express demand cannibalization $[1,9,16,26,31,33,39,40,42,44,56,57]$. In which, consumers have valuation $U \in[0,1]$ for the new product and $\theta U$ for the remanufactured product. Early, Ferguson [16] proposed that OEM should take into account the encroachment of remanufactured products on the sales of new products, and strategies to resist remanufacturers' entry into the market should be put forward. Örsdemir et al. [42] considered the remanufacturing competition between the OEM and TPR and, besides economic impacts, they argued that environmental impact is reduced when the remanufacturer is the OEM. Subsequently, part of the research focuses on competition in remanufacturing recycling channels between OEM and TPR $[22,26,57]$, price competition between new and remanufactured products [40,42], and quality differentiation $[37,39,44,56]$. More recently, Jin et al. [31] demonstrated that third-party remanufacturing could be beneficial to the OEM because of reductions in the price of components provided by supplier. Qian et al. [44] argued that products upgrading strategy can mitigate cannibalization problems and create an optimal pareto improvement for both OEM and TPR. He et al. [26] propose two coordination mechanisms to ameliorate the decentralized model and alleviate competition. Li et al. [37] considered a manufacturer facing the decision of investing in either product quality improvement or in remanufacturing its used products. In this context, our research contributes to this stream of research by not only consider the competition relationship between OEM and TPR, but also explores a new way of cooperation relationship between OEM and TPR.

The interactions between OEM and TPR are modelled as a Stackelberg game, which OEM as a leader and TPR as a follower. This Stackelberg competition game is followed by the work of other studies $[4,15,31,44,56,57,63]$. 
The way of using Stackelberg game is that OEM has a first-mover advantage while TPR move sequentially as a follower. The Stackelberg game not only reflects the OEM in the actual situation as the industry leader $[44,56]$, but also show that the OEM has the initiative power of charging a license fee for TPR's remanufacturing or wholesale price for recycling components $[4,15,63]$. From another perspective, some literature show that TPR remanufacturing as a new entrant brings the problem of cannibalism to OEM products. It also proves that TPR is in the follower position in the Stackelberg game. Research involved in such competition between OEM and TPR are widely investigated with respect to the variation of production cost of remanufacturing. Following the previous literature, we also use these variables in the analysis to exhibit the level of competition between OEM and TPR.

The second stream of literature focuses on the Product Life Cycle and Life Cycle Assessment. The concept of product life cycle (PLC) was first proposed by Levitt and appears in the field of economic and management [35]. PLC can be divided into four phases: introduction, growth, maturity and decline [47]. With the development of supply chain management and environmental problems are paid more attention, PLC can be extended to include product design, manufacturing, use and scrap [43,45]. Besides, since remanufacturing can extend the life cycle of products. PLC of remanufactured product also contains recycling and remanufacturing $[1,13,19,44]$. We assume that our model in this paper can also be viewed as the PLC of remanufactured products, which includes manufacturing, remanufacturing, usage, recycling and disposal [2]. Further, to assess the environmental impacts along the PLC of remanufactured products, a large number of scholars have used Life Cycle Assessment (LCA) techniques to study environmental problems in the field of remanufacturing $[2,14,24,25,44,57,60]$. Although energy consumption, non-renewable raw material consumption, carbon emissions, toxicity can measure the environment, Life Cycle Assessment (LCA) techniques are popular for this purpose in the field of environmental economics [3]. Specifically, Atasu et al. [2] use a single, aggregate measure of environmental impact per unit at each stage of the life cycle to measure environmental impact. Esenduran et al. [13] also measure the impact of take-back legislation on the environment through an approach based on life cycle Assessment. Zhi et al. [60] investigated the environmental impact of the product by using LCA-based approach to characterizes the environmental impact of the fund policy. Following the above article, we also use LCA to measure the environment impact of new and remanufacturing products by shareholding operation caused by OEM. In this context, following previous research $[14,57,60]$, we define environmental impact to be linear in sales quantity, everything else being equal, to reflect the notion that higher quantities of products typically represent the need for larger quantities of virgin materials and bring more environment impacts.

The third part of literature is on forward shareholding. Admittedly, the competitive relationship between the OEM and the third party can effectively be coordinated via external means, such as reward and punishment mechanisms, contract mechanisms, government coordination policies, subsidies and legislation [3, 14, 18, 62]. However, Reitman [46] supported the notion that, in order to commit to less aggressive competition, partial ownership with the competitor is an advantageous arrangement. After minority shareholding among firms, the supply chain is essentially only a part partially integrated supply chain. Therefore, our work is also related to the literature on the revenue-sharing contract, where Cachon [8] and Chauhan [10] proposed a general theoretical framework for this contract type. Subsequently, the coordination of revenue-sharing contracts has been studied extensively under varying conditions [5,29]. Moreover, we combed the literature on partial ownership fields $[7,17,27,34,41,48,57]$. These studies focused on the impact of cross-shareholdings on the performance of the supply chain among enterprises under the condition of Cournot competition. Furthermore, $\mathrm{Fu}$ [17], Gomes [21] and Ghosh and Morita [20] studied the economic performance and the outcomes of competition in terms of partial vertical ownership. These articles emphasize the impact of holding proportion in equity and equity holding cost on the conclusion In order to highlight the value of "shareholding" variables in our operation management investigation we focus on the parameters: the equity holding cost to reflect the efficiency of shareholding Despite the prevalence of partial ownership in the literature, however, little theoretical work has been conducted on the phenomenon of remanufacturing.

By analyzing the abovementioned literature, to the best of our knowledge, we found that little research has been conducted on remanufacturing operations incorporating equity participation. Essentially, our paper 
TABLE 1. Description of related symbols.

\begin{tabular}{ll}
\hline \hline Superscript & Description \\
\hline$N$ & Model $N$ : OEM only use patent license to control TPR \\
$S$ & Model $S$ : OEM is in partial ownership with the TPR \\
\hline Variables & Notation \\
\hline$q_{n} / q_{r}$ & Sales quantity of the new/remanufactured product \\
$p_{n} / p_{r}$ & The market clearing price for the new/remanufactured product \\
$f$ & Patent license fee per remanufactured product \\
\hline Parameters & Notation \\
\hline$c_{n} / c_{r}$ & The marginal cost to produce the new/remanufactured product \\
$\theta_{n} / \theta_{r}$ & Consumer perception discount toward new/remanufactured products \\
$\lambda$ & The holding proportion of OEM in equity \\
$r$ & The equity holding cost \\
$\pi_{m} / \pi_{3 p}$ & Profits for OEM and TPR \\
$\Pi$ & The industry profits \\
$\mathrm{CS}$ & Total consumer surplus for new and remanufactured products \\
$E$ & Environmental total impact \\
$I$ & The relative pollution ratio of remanufactured products \\
$*$ & The equilibrium results of decision variables \\
\hline
\end{tabular}

discusses the production of new products in a decentralized supply chain system with consideration for the situation of an OEM forward shareholding to a TPR producing remanufactured products. Several authors, Fu [28], Hunold and Stahl [30], and Chen et al. [11] have addressed the backward shareholding issues in terms of economics and mergers, which have put the partial vertical ownership into coordination and optimization of the channel and supply chain; however, the impact on firms' remanufacturing business and forward shareholding has not been studied sufficiently. Additionally, we extend our model to examine the impact on closed-loop supply chains with partial ownership and environmental effect, thereby offering a substantial complementary choice for firms compared with the previous literature on the topic.

In summary, this paper makes the following major contributions to the field, which distinguishes it from previous studies: (1) This paper explores a new way for OEMs to participate in remanufactured business - i.e., the control of remanufactured products by TPRs through a shareholding operation popular in other industries; and, (2) it compares two distinct operations to control remanufacturing from the perspective of production decisions, profits and environmental impacts. In short, the innovation inherent in this study is that we consider the ownership characteristics in forward shareholding supply chain, and a comparative analysis is carried out from the perspective of economic and environmental benefits whereby some suggestions for the formulation and implementation of remanufacturing are presented.

\section{THE MODEL HYPOTHESES}

This section describes the hypotheses and notations. Our decision variables are quantity of the new/remanufactured product and license fee per remanufactured product. Our main conclusion is based on the comparison of these parameters. The remaining parameters associated with consumers' willingness to pay, production cost, proportion in equity and equity holding cost are used to influence the variable itself, which we will be explained in the following items. We summarize all the notations in Table 1 and each variable is explained in detail in the following item. 


\subsection{Consumer behaviors}

In this study, we assume the existence of a continuum of consumers who typically differ in their willingness to pay, and the size of the consumer population is assumed to be constant over time and is normalized to 1. To capture consumers who differ in their willingness to pay, we suppose that consumers are heterogeneous in the utility that they derive from consumption and are characterized by their type $u$, which is heterogeneous and uniformly distributed in $[0,1]$. Specifically, a consumer will value the product in reserved willingness to pay, $U$, for a given product $i$ is defined by $U=\theta_{i} u-p_{i}, p_{i}$ is the market clearing price, and $\theta_{i}\left(\theta_{n}\right.$ and $\left.\theta_{r}\right)$ indicates the discount of consumers' perceptions toward new and remanufactured products, respectively. We assume that $\theta_{n}=1$ and $\theta_{r}=\theta<1$. The reason is that the consumer will discount the value of remanufactured products than that of new products $[1,15]$ (i.e., the price of a remanufactured iPhone 7 is always lower than that of new iPhone 7 [44]). To obtain tractable results, we let $\theta_{n}=1$ and $\theta_{r}=\theta<1$ without loss of generality. Thus, one consumer is willing to pay for the new good from OEM derive a net utility of $U_{n}=u-p_{n}$; other with lower values $U_{r}=\theta u-p_{r}$ belong to the remanufactured products. Thus, the indifferent point between purchasing a new product or a remanufactured product is at $\left(p_{n}-p_{r}\right) /(1-\theta)$. In this case, only consumers with valuations in the interval $\left(p_{n}-p_{r}\right) /(1-\theta)<U<1$ will buy new products. The quantity is $q_{n}=1-\left(p_{n}-p_{r}\right) /(1-\theta)$ Similarly, the indifferent point between purchasing a remanufactured product and not purchasing is at $p_{r} / \theta$. In this case, only consumers with valuations in the interval $p_{r} / \theta<U<\left(p_{n}-p_{r}\right) /(1-\theta)$ will buy remanufactured products. The quantity is $q_{r}=\left(p_{n}-p_{r}\right) /(1-\theta)-p_{r} / \theta$. Finally, consumers with valuations lower than $p_{r} / \theta$ would not purchase. Then, after the simplification, we obtain the reversed demand functions for the new and remanufactured product, respectively, in equation (3.1):

$$
\begin{aligned}
p_{n} & =1-q_{n}-\theta q_{r} \\
p_{r} & =\theta\left(1-q_{n}-q_{r}\right) .
\end{aligned}
$$

\subsection{Cost structure}

Similar to the majority of the literature on the closed-loop supply chain [31,44], we assume that all players are risk-neutral and profit-seeking. Furthermore, we assume the OEM to be a Stackelberg leader to maximize its profit with common knowledge of the demand and cost information of new products $\left(c_{n}\right)$. In addition, we assume that the marginal cost for TPR to produce a remanufactured product is $\left(c_{r}\right)$. To ensure the TPR is incentivized to engage in this business and to make a remanufactured product, we further assume $c_{n}>c_{r}>0$. This assumption reflects that remanufacturing process requires only part of the new component because of collecting the serviceable parts, thereby making the remanufacturing product cost cheaper.

Additionally, the OEM will choose proportion in equity $\lambda$ to maximize his own profits, using an equity investment cost described by the cost function $C=\int_{0}^{\lambda} r \lambda \mathrm{d} \lambda=\frac{1}{2} r \lambda^{2}$, which is composed of the holding proportion in equity $\lambda$ and equity holding cost $r$. Here, $r$ represents the obstacle of shareholding activities among competitors (i.e., the cost of integration between negotiations, corporate culture and business activities among enterprises). Consequently, the cost is an integral function that represents the following: the higher the proportion of an OEM's stake in a TPR, the higher the marginal cost of holding it. We ignore the cost of undertaking the collection of the product because the take-back channel and technology have been welldeveloped, and we focus on the impacts of remanufacturing on the forward supply chain $[15,37,55]$.

\subsection{Environmental impact}

This study addresses environmental impact using an LCA-based approach, which is a technique that assesses a product's environmental impact over its entire life cycle, including its manufacture from raw materials to new products, its use, and its disposal [13]. Following recent work in the area of environmental implications for operations management $[1,60]$, the impact during the stages of manufacturing, remanufacturing, usage, recycling (proper disposal by the TPR), and disposal (by consumer) is considered separately, and the subscripts $i \in(n, r, u, c, d)$ are used to represent each stage, respectively. Let $e_{i}$ denote the environmental impact of one 
product in stage $i$. The total environmental impact of new products and remanufactured products is represented by $E_{n}=e_{n} q_{n}$ and $E_{r}=e_{r} q_{r}$, the environmental impact of usage is represented by $E_{u}=e_{u}\left(q_{n}+q_{r}\right)$, and the environmental impact of recycling and disposal is represented by $E_{c}=e_{c}\left(q_{c}-q_{r}\right)$ and $E_{d}=e_{d}\left(q_{n}-q_{c}+q_{r}\right)$. Furthermore, in our study, we assume that all collected products can be used for remanufacturing - that is, $q_{c}=q_{r}[24,44]$. The total environmental impact is $E=E_{n}+E_{r}+E_{u}+E_{c}+E_{d}=\left(e_{n}+e_{d}+e_{u}\right) q_{n}+\left(e_{r}+\right.$ $\left.e_{u}\right) q_{r}$. It is important to note that, since remanufacturing requires less material and energy compared with the manufacturing of new products, we further assume that the per-unit environmental impact of a new product is larger than that of a remanufactured one (essentially, $e_{n}>e_{r}$ ).

\subsection{OEM and TPR}

In this study, we consider a supply chain consisting of one OEM (referred to as he) and one TPR (referred to as she). We assume that OEM is a market Stackelberg leader and sells new products to the consumer, and that TPR sells remanufactured products. Such assumption reflected the fact that OEM usually have preferential pricing, bargaining power and the ability to choose whether or not buy into TPR's share. This assumption is also reflected in practice, as BMW outsourced the processing of end-of-life vehicles to TPR and gave them the proprietary right to do so. Sun used license availability for its used products as a means of controlling the remanufacturing channel and reverse channel $[32,57]$. Therefore, although OEM and TPR can simultaneously determine $q_{n}$ and $q_{r}$ to maximize their profits, OEM still have the first-move advantage to charge a license fee. Then we developed two models of the OEM regulating its remanufacturing operations to the external third-party remanufacturer: (i) Model $N$, where the OEM controls the remanufacturing operations to a TPR via charging a license fee $(f)$; and, (ii) Model $S$, where the OEM is not only a licensee, but also a holding firm requiring the TPR to share their profits according to the equity held $(\lambda)$.

Two partial ownership assumptions frame our analysis. First, we examine ownership interests that convey no control over the target's decision-making, which means $(0<\lambda<1 / 2)$. Second, we assume the target chooses its action (i.e., output quantity) after the shareholder has obtained its interest. This reflects the stylized fact that corporate equity holdings typically adjust less often than prices and other short-term strategic variables $[23,28,34]$. Thus, the decision processes is as follows. First, the OEM decides whether or not engage in shareholding operation in TPR. Then, the OEM as a Stackelberg leader announces its patent license fees $(f)$ charged per remanufactured product. Following this, the OEM and TPR maximize their profits by determining the optimal units of their production quantities of new and remanufactured products $\left(q_{n}\right.$ and $\left.q_{r}\right)$ separately and simultaneously. Such competition has also been used widely in the economics and management literatures in terms of remanufacturing business $[16,55,56]$. Accordingly, the model is solved through backward induction.

\section{MOdeL}

This section presents a decision-making model for the OEM. It presents the question: Should the OME become a shareholder of TPR? Specifically, the OEM has the alternative to become a shareholder (Model $S$ : Fig. 1b) or not (Model N: Fig. 1a).

\subsection{Model $N$}

In this operation, the OEM prefers to regulate the TPR only with the patent license. Specifically, in the Figure 1a, the OEM maximizes his profits by announcing a license fee to the TPR and output of new products. Thus, the OEM's problem is:

$$
\max _{f, q_{n}} \pi_{m}^{N}\left(f, q_{n}, q_{r}\right)=\left(p_{n}-c_{n}\right) q_{n}+f q_{r} .
$$

The first term of the equation (4.1) represents the OEM's revenue from new product, and the second term is the patent license revenue from remanufactured product. Then, given the patent license fee $\left(f^{N *}\right)$ and in 


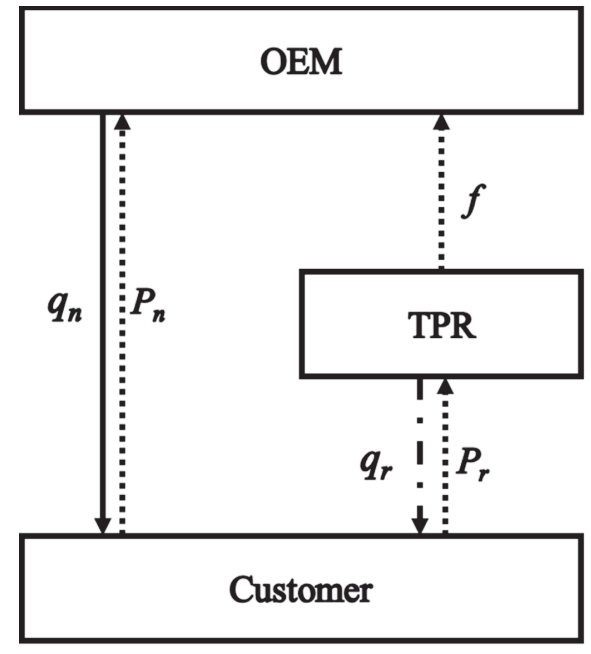

(a)

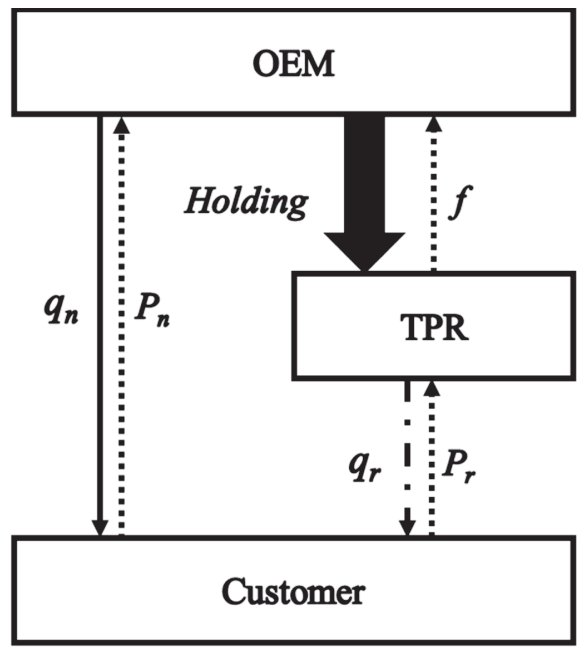

(b)

New Products

Remanufactured Products

........sh Flows...

Figure 1. The flow of two models. (a) Model $N$. (b) Model $S$.

anticipation of the OEM's response $\left(q_{n}^{N *}\right)$, the issue for the TPR subsequently becomes:

$$
\max _{q_{r}} \pi_{3 p}^{N}\left(f, q_{n}, q_{r}\right)=\left(p_{r}-c_{r}-f\right) q_{r} .
$$

Using backward induction, and once the OEM can maximize his profit by choosing $\left(q_{n}^{N *}\right)$, the TPR can also do so by choosing the remanufactured products $\left(q_{r}^{N *}\right)$. Following this, the OEM can choose the patent license fee $\left(f^{N *}\right)$. The equilibrium decisions are summarized in the Table A.1.

Lemma 4.1. Under License fee operation, there exists the influence of various parameters on output and pricing decision (Proof see Appendix A.1).

Considering $q_{n}^{N *}>0, q_{r}^{N *}>0$ and $f^{N *}>0$, the cost of remanufacturing is $\left(8 c_{n}+3 k-c_{n} k-8\right) / 2<c_{r}<c_{n} k$. This shows that the equilibrium solutions are economically feasible. Furthermore, the equilibrium output and pricing decisions depend on the parameters $\theta, c_{n}$ and $c_{r}$. Under Model $N$, an increased consumer perception discount on remanufactured products create a higher price and output among the remanufactured products, but reduces them in new products. The increase in the cost of manufacturing/remanufacturing reduces the sales quantity of new/remanufactured products, respectively, but increases the price of new and remanufactured products (see Tab. 2).

\subsection{Model $S$}

In this operation, the OEM is in partial ownership with the TPR and, consequently, the profit of remanufactured product needs to be shared. Here, in the Figure 1b, OEM as an investor, have two influences on TPR. (1) OEM will provide the technology to reduce the production costs associated with remanufacturing. (2) TPR will be required to share the profit of the remanufactured product according to the equity held by OEM. Accordingly, before shareholding operation, we can have the profits function for the TPR are same like Model $N$ :

$$
\pi_{3 p}^{S}=\left(p_{r}-c_{r}-f\right) q_{r}
$$


TABLE 2. Influence of parameters on the output and pricing decisions under Model $N$.

\begin{tabular}{lcccc}
\hline \hline & \multicolumn{4}{c}{ Variable } \\
\cline { 2 - 5 } Parameter & $q_{n}^{N *}$ & $q_{r}^{N *}$ & $p_{n}^{N *}$ & $p_{r}^{N *}$ \\
\hline$\theta \nearrow$ & $\searrow$ & $\nearrow$ & $\searrow$ & $\nearrow$ \\
$c_{n} \nearrow$ & $\searrow$ & $\nearrow$ & $\nearrow$ & $\nearrow$ \\
$c_{r} \nearrow$ & $\nearrow$ & $\searrow$ & $\searrow$ & $\nearrow$ \\
\hline
\end{tabular}

Notes. The signs $\nearrow, \searrow$ and $X$ represent the relationships as monotonically increasing, monotonically decreasing and unrelated with respect to the parameter, respectively.

After OEM becomes a shareholder of TPR, with $\lambda$ representing portion equity, the cost of the remanufactured product declines $\lambda c_{r}$ due to the technology of OEM and his familiarity with the disposal components. As a result, the TPR needs to share the $\lambda$ portion of her profits with OEM. Thus, the profits function for TPR becomes the rest of the $1-\lambda$ portion of her profits:

$$
\max _{q_{r}} \pi_{3 p}^{S}\left(f, q_{n}, q_{r}\right)=(1-\lambda)\left(p_{r}-(1-\lambda) c_{r}-f\right) q_{r} .
$$

And then, the profits function for OME becomes:

$$
\max _{f, q_{n}} \pi_{m}^{S}=\left(p_{n}-c_{n}\right) q_{n}+f q_{r}-\frac{1}{2} r \lambda^{2}+\lambda\left(p_{r}-(1-\lambda) c_{r}-f\right) q_{r}
$$

Where, the first term of the equation (4.5) represents the OEM's revenue from the new product, the second term represents the cost of equity held, and the last term represents the $\lambda$ portion of profits from the TPR. Again, with the use of backward induction, the equilibrium decisions are summarized in the Table A.1.

Lemma 4.2. Under the Shareholding operation, there exists the influence of various parameters on output and pricing decision (Proof see Appendix A.2).

Considering $q_{n}^{S *}>0, q_{r}^{S *}>0$ and $f^{S *}>0$, the cost of remanufacturing is $-\left(4 a+8 c_{n}+3 k-4 a c_{n}+2 a k-\right.$ $\left.c_{n} k-a^{2} k+a^{2} c_{n} k-8\right) /\left(2\left(a^{2}-1\right)\right)<c_{r}<c_{n} k /(1-a)$. This illustrates that the equilibrium solutions are economically feasible. The equilibrium output and pricing decisions depend on the parameters $\lambda, \theta, c_{n}$ and $c_{r}$. Under Model $S$, the proportion of shares for the OEM $\lambda$ increases the sales quantity of remanufactured products, but reduces the output of new products. Additionally, $\lambda$ does not affect the pricing of new products. Furthermore, an increased consumer perception discount on remanufactured product triggers a higher price and output in remanufactured products, but reduces them in new products. The increase in the cost of manufacturing/remanufacturing reduces the sales quantity of new/remanufactured products, respectively, but increases the price of new and remanufactured products (see Tab. 3).

Lemma 4.3. Under the Shareholding operation, there exists an upper boundary on the equity holding cost i.e., $r<\bar{r}$ (Proof see Appendix A.2).

Considering $\pi_{3 p}^{S *}>0$, the equity holding cost is $r<\bar{r}=\left(4 c_{r}^{2}-8 \lambda c_{r}^{2}+4 \lambda^{2} c_{r}^{2}+8 \theta-4 \lambda \theta-16 c_{n} \theta+8 \lambda c_{n} \theta+8 c_{n}^{2} \theta-\right.$ $\left.4 \lambda c_{n}^{2} \theta-8 c_{n} c_{r} \theta+8 \lambda c_{n} c_{r} \theta-3 \theta^{2}-2 \lambda \theta^{2}+\lambda^{2} \theta^{2}+6 c_{n} \theta^{2}+4 \lambda c_{n} \theta^{2}-2 \lambda^{2} c_{n} \theta^{2}+c_{n}^{2} \theta^{2}-2 \lambda c_{n}^{2} \theta^{2}+\lambda^{2} c_{n}^{2} \theta^{2}\right) /\left(16 \lambda^{2} \theta-\right.$ $\left.8 \lambda^{3} \theta-6 \lambda^{2} \theta^{2}-4 \lambda^{3} \theta^{2}+2 \lambda^{4} \theta^{2}\right)$. This demonstrates that it is economically feasible for the OEM to be in ownership with the TPR. This also demonstrates that the OEM cannot heedlessly own the shares of other firms without considering the cost of equity. Table 4 illustrates that, when the OEM observes the remanufacturing cost of the TPR increases, the upper boundary of the cost of equity is lowered. That is, this restricts its own operation in a narrow range equity cost. However, an increased consumer perception discount on remanufactured product creates a higher upper boundary because the OEM prefers to become a shareholder, as the TPR's remanufactured products are more acceptable to consumers (see Tab. 4). 
TABLE 3. Influence of parameters on the output and pricing decisions under Model $S$.

\begin{tabular}{lcccc}
\hline \hline & \multicolumn{4}{c}{ Variable } \\
\cline { 2 - 5 } Parameter & $q_{n}^{S *}$ & $q_{r}^{S *}$ & $p_{n}^{S *}$ & $p_{r}^{S *}$ \\
\hline$\lambda \nearrow$ & $\searrow$ & $\nearrow$ & $\searrow$ & $\searrow$ \\
$\theta \nearrow$ & $\searrow$ & $\nearrow$ & $\searrow$ & $\nearrow$ \\
$c_{n} \nearrow$ & $\searrow$ & $\nearrow$ & $\nearrow$ & $\nearrow$ \\
$c_{r} \nearrow$ & $\nearrow$ & $\searrow$ & $\searrow$ & $\nearrow$ \\
\hline
\end{tabular}

Notes. The signs $\nearrow, \searrow$ and $X$ represent the relationships as monotonically increasing, monotonically decreasing and unrelated with respect to the parameter, respectively.

TABLE 4. Influence of parameters on the upper boundary.

\begin{tabular}{llccc}
\hline \hline & \multicolumn{4}{c}{ Parameter } \\
\cline { 2 - 4 } Upper boundary & $\lambda \nearrow$ & $\theta \nearrow$ & $c_{n} \nearrow$ & $c_{r} \nearrow$ \\
\hline $\bar{r}$ & $\times$ & $\nearrow$ & $\times$ & $\searrow$ \\
\hline
\end{tabular}

Notes. The signs $\nearrow, \searrow$ and $X$ represent the relationships as monotonically increasing, monotonically decreasing and unrelated with respect to the parameter, respectively.

\section{AnAlysis}

This section comparatively analyzes the practicability of the shareholding operation schemes in terms of three aspects: output decisions, economic benefits, and environmental benefits.

\subsection{Comparison of equilibrium solutions}

Proposition 5.1. When $c_{n}<c_{n_{1}}$, the OEM is likely to decrease the patent license fee if $c_{r}<c_{r_{1}}$ and increase the patent license fee if $c_{r}>c_{r_{1}}$. When $c_{n}>c_{n_{1}}$, the OEM always increases the patent license fee (Proof see Appendix A.3).

Based on Proposition 5.1, the OEM decreases the license fee if the production cost of both new and remanufactured products is relatively low due to less of an influence on profits. When the cost of remanufacturing products exceeds $c_{r_{1}}$, the OEM increases his license fee. This is because the OEM offers technical support to reduce the cost of remanufactured goods after being in partial ownership with the TPR. The OEM participates in the remanufacturing process and bears the cost. Moreover, the OEM usually sets a higher patent license fee for the TPR. When the production cost of new products becomes significant $\left(c_{n}>c_{n_{1}}\right)$, the OEM still sets a higher license fee for the TPR to compensate for the technological support he has given to the TPR.

Proposition 5.2. The Shareholding operation always brings positive remanufactured product sales growth $\left(q_{r}^{S *}>q_{r}^{N *}\right)$ but reduces the sales of new products $\left(q_{n}^{S *}<q_{n}^{N *}\right)$. Additionally, the shareholding operation expands overall sales volume $\left(q_{n}^{S *}+q_{r}^{S *}>q_{n}^{N *}+q_{r}^{N *}\right)$ (Proof see Appendix A.4).

Proposition 5.2 shows that the shareholding operation offers advantages in generating an increased quantity of remanufactured products but a decrease in new products. This is due to two reasons: First, the OEM is more concerned about his profits in remanufactured product due to profit sharing under the shareholding operation and, thus, the sale of remanufactured products increases; Second, remanufactured products encroach on the market of products, thus weakening the advantages of the new products. However, we have still demonstrated that the volume of products expands, meaning that, in the case of the shareholding operation, an increase in the quantity of remanufactured products is capable of compensating for the loss in new products. 


\subsection{Comparison of economic benefits}

To better understand the effect of the shareholding operation on all parties in the supply chain, and to assist in selecting a better operation, in this section we highlight economic benefits from two main perspectives: Is the shareholding operation more beneficial to the OEM and the TPR, and, in particular, is this operation well supported on a whole-industry scale?

Proposition 5.3. There exists a threshold such that, if $r<r_{1}$, the profits for the OEM in Model $S$ are higher than those in Model $N$ (i.e., $\left.\pi_{m}^{S *}>\pi_{m}^{N *}\right)$. Otherwise, if $r_{1}<r<\bar{r}$, these profits are lower $\left(i . e ., \pi_{m}^{S *}<\pi_{m}^{N *}\right)$ (Proof see Appendix A.5).

Proposition 5.3 demonstrates that the OEM would benefit more when the equity holding cost is relatively small. This situation occurs for two reasons. First, when the equity holding cost is relatively high $\left(r_{1}<r<\bar{r}\right)$, which means the reorganization of assets, personnel mobilization and business integration are difficult to carry out between the OEM and TPR smoothly. Second, the shareholding operation can create an increase in sales volume of this series of products, which results in more intense market competition (refer to Prop. 5.2). Therefore, the shareholding operation is regarded as prohibitive for the OEM unless the costs are low enough and the profit share from the TPR is effective in compensating for the loss of profits from the current product.

Proposition 5.4. It is less profitable for the TPR under the shareholding operation when $c_{r}<c_{r_{2}}$, with essentially $\pi_{3 p}^{S *}<\pi_{3 p}^{N *}$. Otherwise, if $c_{r}>c_{r_{2}}, \pi_{3 p}^{S *}>\pi_{3 p}^{N *}$ (Proof see Appendix A.6).

Based on Proposition 5.4, when $c_{r}<c_{r_{2}}$, the shareholding operation is less beneficial for the TPR. Conventional wisdom suggests that the low cost is conducive to third-party remanufacturing, and third-party remanufacturing always hurts the OEM (as illustrated in the literature $[34,36,38,51,52,59,61]$ ). However, if the OEM decides to become a shareholder and invest in a third-party, he can benefit more from the business of remanufacturing. Therefore, if the cost of remanufacturing is relatively small, the TPR needs to distribute profits to the OEM. Consequently, the TPR may not welcome ownership from the OEM. When the cost of remanufacturing is significant $\left(c_{r}>c_{r_{2}}\right)$, the TPR can benefit from partial ownership from the OEM as a result of an observable decline in remanufacturing cost through the use of the OEM's technology.

Proposition 5.5. When $c_{r}<c_{r_{2}}, r_{2}<r<r_{1}$, the shareholding operation is always detrimental to the industry - i.e., $\Pi^{S *}<\Pi^{N *}$. Otherwise, when $r<r_{2}$, and $\Pi^{S *}>\Pi^{N *}$ (Proof see Appendix A.7).

Propositions 5.3 and 5.4 show that shareholding operation may be beneficial to the OEM (i.e., $\left.r<r_{1}\right)$ but may be detrimental to the TPR (i.e., $c_{r}<c_{r_{2}}$ ). While this proposition shows when $c_{r}<c_{r_{2}}, r_{2}<r<$ $r_{1}$, the shareholding operation is always detrimental to the industry. This further indicates that the benefits for the OEM's profitability (see Prop. 5.3) cannot compensate for the TPR's loss in profits (see Prop. 5.4). On the contrary, when the equity holding cost is lower than $r_{2}$, the whole industry can benefit from shareholding (Model $S$ ).

\subsection{Comparison of environmental benefits}

In this section, we answer the question, what is the environmental impact of the OEM's shareholding operation on TPR's remanufacturing? And under what conditions an economic and environmental win-win situation can be achieved in terms of shareholding operation? To better understands the effect of the shareholding operation on the environment, we use the LCA-based approach to assesses a product's environmental impact over its entire life cycle. In Section 3.3, following literature [14,44,60], we define $E=E_{n}+E_{r}+E_{u}+E_{c}+E_{d}=$ $\left(e_{n}+e_{d}+e_{u}\right) q_{n}+\left(e_{r}+e_{u}\right) q_{r}$. For simplicity, we set $e_{1}=e_{n}+e_{d}+e_{u}$ and $e_{2}=e_{r}+e_{u}$, where $e_{1}$ and $e_{2}$ represent the per-unit environmental pollution associated with a new and a remanufactured product in their entire life cycle. Obviously, $e_{1}>e_{2}$. In this context, the lower is the environmental impact, the more environmentally friendly is the model. When comparing the equilibrium environmental impact of the two models, we arrive at the following proposition: 
Proposition 5.6. When $0<e_{2} / e_{1}<I$, the shareholding operation is superior in environmental impact $\left(E^{S}<E^{N}\right)$. When $I<e_{2} / e_{1}<1$, the environmental impact in Model $S$ is greater than in Model $N:\left(E^{S}>E^{N}\right)$ (Proof see Appendix A.8).

Based on Proposition 5.6, when the environmental pollution associated with a remanufactured product is relatively small $\left(0<e_{2} / e_{1}<I\right)$ the shareholding operation provides a greener solution compared with Model $N$. Although compared to Model $N$ the OEM (TPR) provides fewer (more) new (remanufactured) products than in Model $S$, based on Proposition 5.2 (with essentially $q_{n}^{S *}<q_{n}^{N *}$ and $q_{r}^{S *}>q_{r}^{N *}$ ), the factor influencing the environment is the per-unit environmental pollution associated with the remanufactured product. In other words, it is essential to control the environmental damage associated with remanufactured products relative to new products.

Corollary 5.7. Compared with Model $N$, the consumer surplus in Model $S$ is always greater (i.e., $\mathrm{CS}^{S}>\mathrm{CS}^{N}$ ). If $0<e_{2} / e_{1}<I, c_{r}>c_{r_{2}}$ and $r<r_{1}$, then the shareholding operation is capable of creating an overall outcome that benefits the economy and the environment (Proof see Appendix A.9).

Consumer surplus consists of two components in our paper: consumers' willingness to pay for the OEM's new products and for the TPR's remanufactured products $[2,42,57,62]$. It is calculated as follows:

$$
\mathrm{CS}=\int_{1-q_{n}-q_{r}}^{1-q_{n}}\left(\theta u-p_{r}\right) \mathrm{d} u+\int_{1-q_{n}}^{1}\left(u-p_{n}\right) \mathrm{d} u .
$$

Comparing the consumer surplus of the two models, Corollary 5.7 shows that, when the OEM becomes a shareholder in the remanufacturing business of the TPR, it is an environmentally-friendly situation for consumers. It is important to note that the OEM cares greatly about the TPR's revenue in the shareholding operation, because it can drive larger volumes of market capacity in Model $S$ than it can in Model $N$ (see Prop. 5.2). In particular, the OEM would allow the TPR to remanufacture products with the aim of earning more profits from those remanufactured products. In other words, the competition between new and remanufactured products in Model $S$ gains more momentum compared with that in Model $N$, which ultimately benefits consumers $\left(\mathrm{CS}^{S *}>\mathrm{CS}^{L *}\right)$.

Corollary 5.7 further reveals that, under certain conditions (i.e., $0<e_{2} / e_{1}<I, c_{r}>c_{r_{2}}$ and $r<r_{2}$ ), the OEM undertaking ownership operations with the TPR can lead to a win-win situation in terms of both economic and environmental benefits within a certain range. More specifically, when remanufacturing is undertaken by a TPR, the OEM as a shareholder does not necessarily harm the third party.

Corollary 5.8. I is influenced by various parameters - specifically, $c_{n}, \lambda$ and $\theta$ have a positive effect on $I$, while $c_{r}$ has a negative effect on I (Proof see Appendix A.10)

Again, Proposition 5.6 indicates that, when the pollution ratio on the environment from remanufacturing is smaller $\left(0<e_{2} / e_{1}<I\right)$, Model $S$ creates less impact on the environment compared with Model $N$. According to the calculation method of environmental pollution based on LCA, the number of new and remanufactured products will determine the pollution level of each model. In our hypothesis, the production of new and remanufactured products is controlled by these parameters (i.e., The marginal cost to produce the new/remanufactured product $c_{n}$ and $c_{r}$, consumer preferences for remanufactured goods $\theta$, and the holding proportion of OEM in equity $\lambda$ ). Therefore, these parameters will further affect the pollution coefficient of the total environment $E=e_{1} q_{n}+e_{2} q_{r}$. Although we have indicated which model is optimal for the range of different pollution ratio $I \in(0,1)$, we also want to explore how the range fluctuations are affected by other parameters.

The outcome of this derivative indicates that pollution ratio $I$ is positively affected by $c_{n}, \lambda$ and $\theta$, but negatively affected by $c_{r}$. That is to say, reducing the cost of remanufacturing, increasing consumer preferences for remanufactured goods or increasing the proportion of the OEM's share in the TPR's equity can increase equilibria pollution ratio $I$, and further cause the applicability of Model $S$ is wide (see Tab. 5). Conversely, the reverse change of these parameters is beneficial to Model $N$. From a practical perspective, if the shareholding 
TABLE 5. Influence of parameters on the pollution rate.

\begin{tabular}{lcccc}
\hline \hline \multirow{2}{*}{ Pollution ratio } & \multicolumn{4}{c}{ Parameter } \\
\cline { 2 - 5 }$I$ & $\lambda \nearrow$ & $\theta \nearrow$ & $c_{n} \nearrow$ & $c_{r} \nearrow$ \\
\hline$I$ & $\nearrow$ & $\nearrow$ & $\nearrow$ & $\searrow$ \\
\hline
\end{tabular}

Notes. The signs $\nearrow, \searrow$ and $X$ represent the relationships as monotonically increasing, monotonically decreasing and unrelated with respect to the parameter, respectively.

operation is executed, managers in the supply chain should pay attention to reducing the remanufacturing cost and increasing the share proportion of the TPR, which is a necessary approach to take to protect the environment.

\section{NumERICAL EXAMPLE AND MANAGERIAL RELEVANCE}

This section analyzes the environmental impacts of product remanufacturing under the two different models by using numerical examples. The analysis not only corroborates the propositions and conclusions presented above, but also offers management insights.

\subsection{Numerical example on equilibrium solutions}

he parameter values are $\lambda=0.1, \theta=0.9$ and $c_{n}=0.8$. To make it economically feasible, $0.3223<c_{r}<0.7200$. Here, we simulate the conclusions of item 5.1 in Figure 2. As Figure 2a illustrates, it is proved that the license fee of OEM between Model $S$ and Model $N$ are different. Figures 2b-2d shows that sales volume of new products of Model $S$ is lower than that of Model $N$, while the remanufactured products sales is higher than Model $N$. Meanwhile, the overall sales are also higher than that of no-shareholding operation. As shown in Lemmas 4.1 and 4.2, these figures also show that the sales quantity of new/remanufactured products decrease/increase with increase in the cost of remanufacturing increases.

\subsection{Numerical example on economic benefits}

The parameter values are $\lambda=0.1, \theta=0.9$ and $c_{n}=0.8$. To make it economically feasible, $0.3223<c_{r}<$ 0.7200. Figure 3a illustrate the OEM's profits comparison between Model $S$ and Model $N$. We find that there exists a threshold $r_{1}=0.3606$; as shown in Proposition 5.3, when $r<r_{1}=0.3606$, the OEM's profits in Model $S$ is higher than that in Model $N$. Particularly, we revalue $\lambda=0.2$ and $\lambda=0.3$ to the holding proportion of OEM in equity. Then, we further find that an increase in holding proportion can improve OEM's profitability (the slope of the red line gets steeper) but reduce the upper limit of the equity holding cost that OEM can tolerate (the point where red line intersects the $X$-axis moves to the left). In other words, the more shares OEM hold, the more production responsibilities and risks OEM have to bear. Therefore, as shown in Figure 3a the upper limit of the equity holding cost $\bar{r}$ decrease. Figure 3b illustrate the TPR's profits comparison between Model $S$ and Model $N$. Obviously, when $0.3223<c_{r}<c_{r_{2}}=0.4213$, the TPR's profits in Model $N$ is higher than that in Model $S$, otherwise, when $0.4213=c_{r_{2}}<c_{r}<0.7200$, the TPR's profits in Model $S$ is higher than that in Model N. In sum, based on Figure 3, we can conclude our results in Propositions 5.3 and 5.4.

\subsection{Numerical example on environmental benefits}

We presented the sensitivity analysis with respect to key parameters $c_{r}, e_{1}$ and $e_{2}$. The parameter values are $\lambda=0.1$ and $\theta=0.9$. We varied one parameter at a time while keeping the others fixed. All results obtained by calculation are presented in Table 6.

Table 6 shows that how environment impact changes with per-unit environmental pollution of remanufactured and new product. First, let's focus on Model $S$ between Table $6 \mathrm{a}$ and b, it reflects that an increasing 


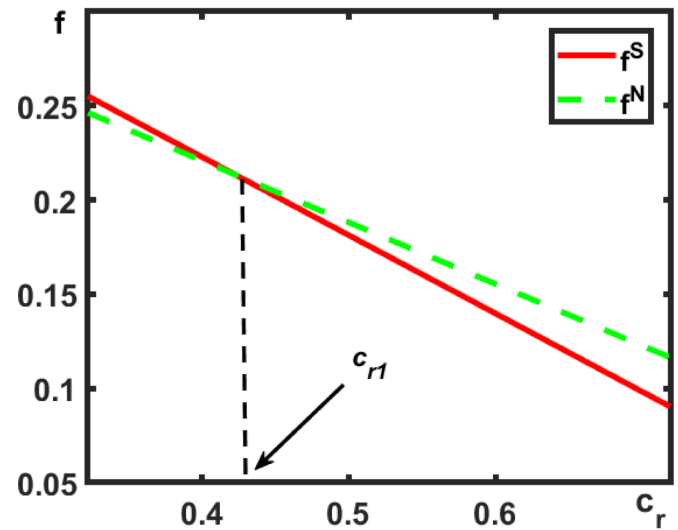

(a)

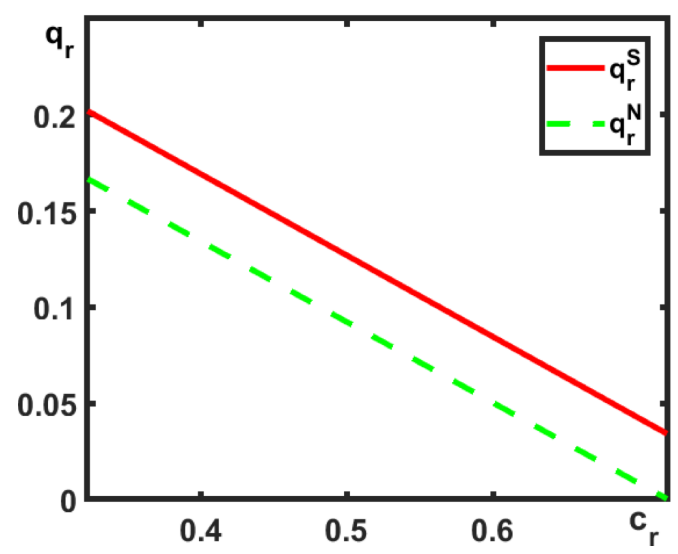

(c)

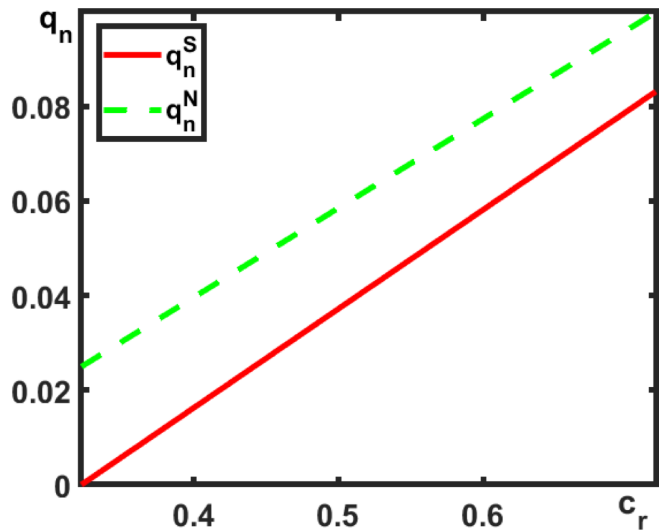

(b)

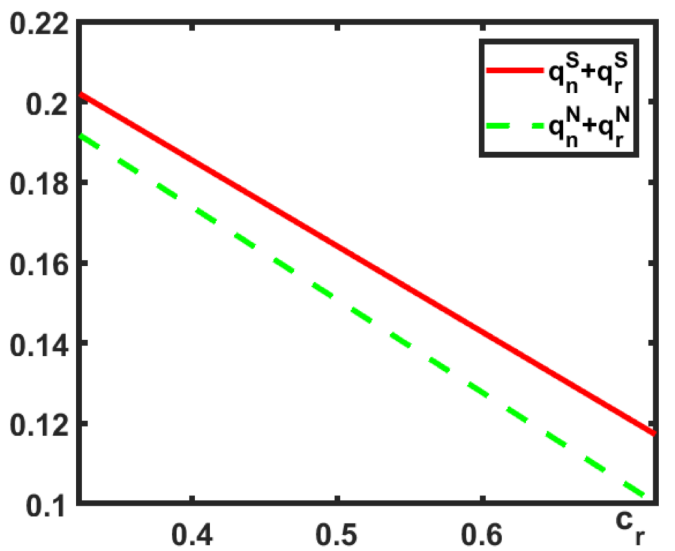

(d)

Figure 2. The effect of $c_{r}$ on the equilibrium solutions. (a) Comparison of $f$. (b) comparison of $q_{n}$. (c) Comparison of $q_{r}$. (d) Comparison of $q_{n}+q_{r}$.

remanufacturing environmental pollution will slightly increase environment impact (from 0.496 to 0.504 ), while an increasing manufacturing environmental pollution increase environment impact of much more (from 0.496 to 0.581). Then, if we concentrate on comparison between $E^{S}$ and $E^{N}$ in Table $6 \mathrm{a}$, we find that when $e_{2}$ increase from 05 to 06. The environment impact of Model $S$ is from 0.0496 to 0.581 , while that of Model $N$ is from 0.0494 to 0.540 . In other words shareholding model actually amplifies the environmental impact of remanufactured goods. On the contrary, we find that when $e_{1}$ increase from 0.9 to 1 in Table $6 \mathrm{~b}$, the environment impact of Model $S$ is from 0.0496 to 0.504 , while that of Model $N$ is from 0.0494 to 0.523 . Shareholding model actually reduce the environmental impact of new goods. In practical, this also reflects that when OEM participate in the equity of TPR (Model $S$ ), OEM should do more to help TPR reduce the environmental pollution of perunit remanufactured products and consequently reduce the overall environmental impact. If OEM decide not to engage in TPR's remanufacturing (Model $N$ ), it is better for the whole supply chain to reduce the environmental pollution of per-unit new products. 


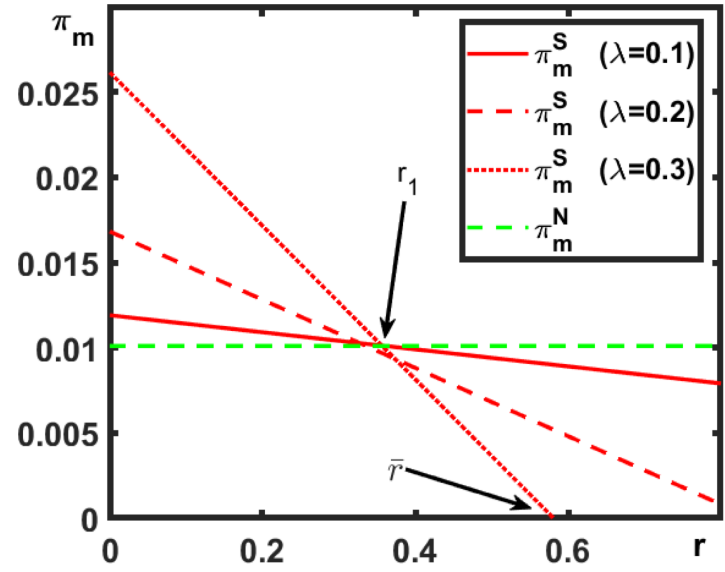

(a)

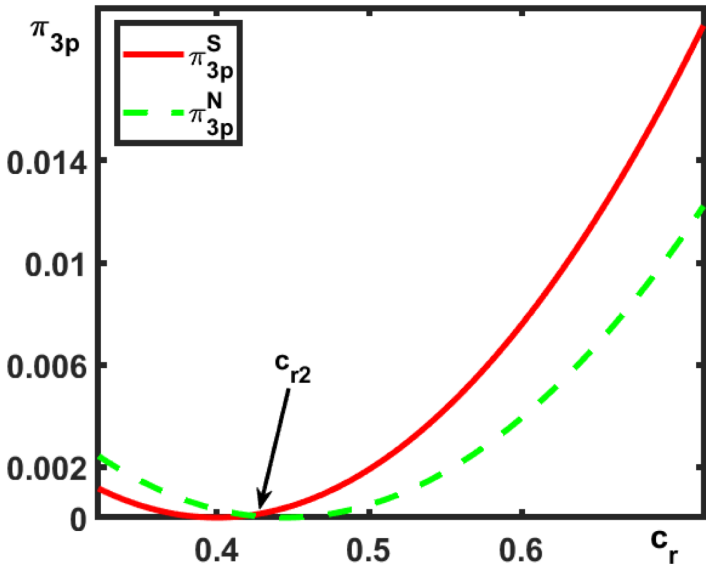

(b)

Figure 3. Comparison of the economic benefits. (a) Comparison of OEM's profits $\pi_{m}$. (b) Comparison of TPR's profits $\pi_{r}$.

TABLE 6. The sensitivity analysis of key parameters.

\begin{tabular}{|c|c|c|c|c|c|c|c|c|c|c|c|}
\hline \multicolumn{6}{|c|}{ (a) The effect of $e_{2}$} & \multicolumn{6}{|c|}{ (b) The effect of $e_{1}$} \\
\hline$c_{r}$ & $c_{n}$ & $e_{1}$ & $e_{2}$ & $E^{S}$ & $E^{N}$ & $c_{r}$ & $c_{n}$ & $e_{1}$ & $e_{2}$ & $E^{S}$ & $E^{N}$ \\
\hline 0.7 & 0.9 & 0.9 & 0.50 & 0.0496 & 0.0494 & 0.7 & 0.9 & 1 & 0.50 & 0.0504 & 0.0523 \\
\hline 0.7 & 0.9 & 0.9 & 0.52 & 0.0513 & 0.0503 & 0.7 & 0.9 & 0.98 & 0.50 & 0.0503 & 0.0517 \\
\hline 0.7 & 0.9 & 0.9 & 0.54 & 0.0530 & 0.0512 & 0.7 & 0.9 & 0.96 & 0.50 & 0.0501 & 0.0511 \\
\hline 0.7 & 0.9 & 0.9 & 0.56 & 0.0547 & 0.0521 & 0.7 & 0.9 & 0.94 & 0.50 & 0.0499 & 0.0506 \\
\hline 0.7 & 0.9 & 0.9 & 0.58 & 0.0564 & 0.0531 & 0.7 & 0.9 & 0.92 & 0.50 & 0.0498 & 0.0500 \\
\hline 0.7 & 0.9 & 0.9 & 0.60 & 0.0581 & 0.0540 & 0.7 & 0.9 & 0.9 & 0.50 & 0.0496 & 0.0494 \\
\hline
\end{tabular}

Notes. Effect of per-unit environmental pollution of remanufactured product $e_{2}$ and of new product $e_{1}$.

Specifically, we then simulate how relative pollution ratio of remanufactured products $I$ change under key parameters. The parameter values are $\lambda=0.1, \theta=0.9$ and $c_{n}=0.9$. To make it economically feasible, $0.6612<c_{r}<0.8100$.

For clarity, we set $e_{1}=1$ and, thus, $e_{2}<1$. Then we compared the impact of the remanufacturing cost and per-unit pollution of remanufactured product on the environment for the two models. As Figure 4 illustrates, when the relative pollution to the environment from remanufactured product is reduced $\left(0<e_{2} / e_{1}<I\right)$, Model $S$ (the red region) pollutes the environment less than does Model $N$ (the green region). Obviously, the impact of the remanufacturing cost on the environment is greater than the per-unit pollution from remanufacturing (the $X$-axis remanufacturing cost appears steeper than $Y$-axis per-unit pollution from remanufacturing in Fig. 4). Therefore, for managers, it is beneficial to the environment to reduce both the pollution and cost of remanufactured products, especially more remanufacturing costs should be cut off.

We use the same data as above $\left(\lambda=0.1, \theta=0.9, c_{n}=0.9\right.$ and $\left.c_{r}=0.7\right)$, but we compare the impact of the per-unit pollution of new product and remanufactured product in the two models on the environment. It is clear that boundary $I$ in Proposition 5.6 has been shown in Figure 5. Additionally, we can easily see that pollution from remanufactured product $\left(e_{2}\right)$ has no significant effect on the environment. However, when new product pollution $\left(e_{1}\right)$ drops, the impact on the environment sharply decreases, which means it is relatively 


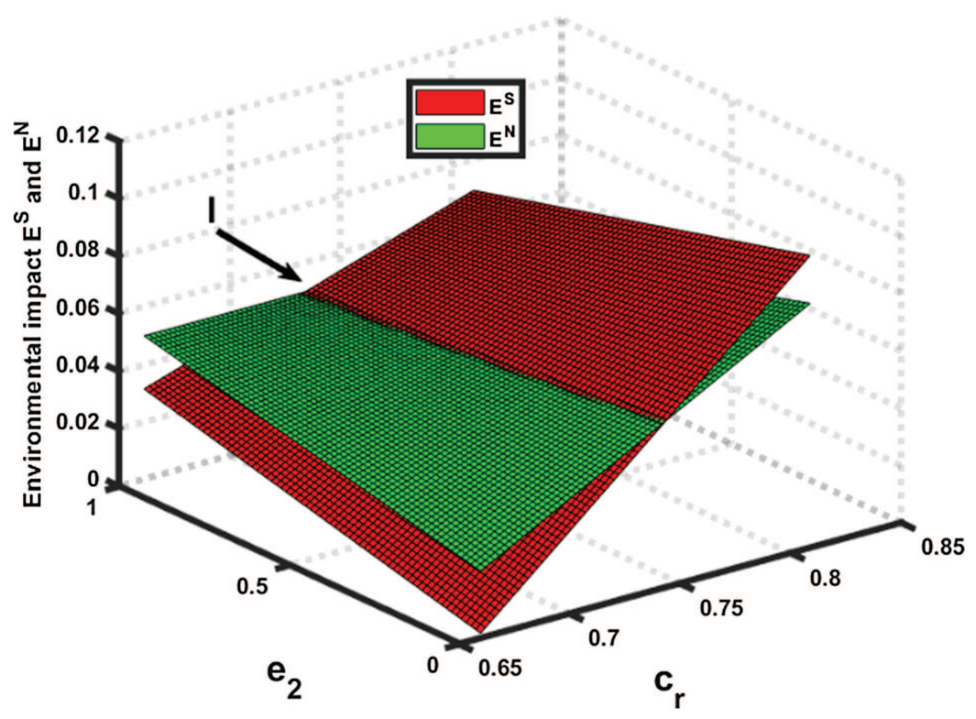

Figure 4 . The effect of and $e_{2}$ and $c_{r}$ on the environment.

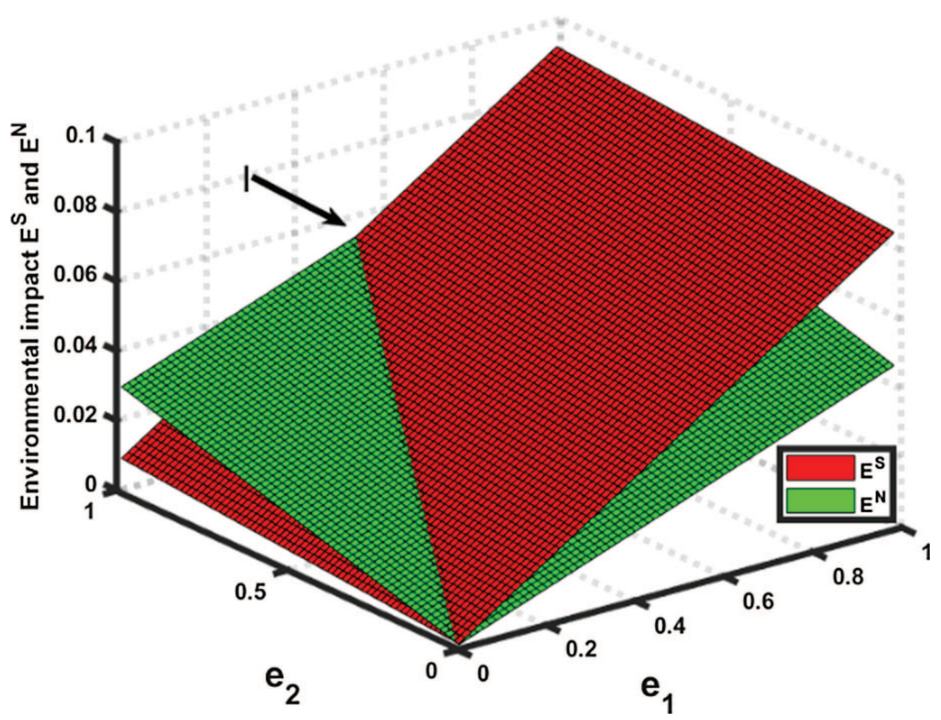

FIGURE 5 . The effect of and $e_{2}$ and $e_{1}$ on the environment.

more important compared with $e_{2}$. Therefore, reducing the pollution generated from the manufacturing of new products is just more important than reducing the pollution generated from remanufactured products. From a practical perspective, Environmental protection is not only the responsibility of remanufacturers (TPRs), but also that of enterprises in the whole supply chain, including OEMs.

\section{Conclusions}

In previous studies, the value and profits of remanufactured products is only understood through the respective businesses of TPRs and OEMs, both of whom are forced into competition with each other. To encourage 
and support the remanufacturing of end-of-life products and to promote the development of a closed-loop supply chain, this paper considers a shareholding operation where the OEM holds a TPR's equity in ownership. We analyze the impact of this operation by building a Stackelberg game model. Specifically, we compared the equilibrium solutions of shareholding operation and that of model where OEM not engage in holding equity. In addition to focusing on the economic benefits, we were also concerned with benefits to the environment.

Our study shows the implications of shareholding operation for remanufacturing in terms of economic and environmental sustainability Therefore we here established the following important conclusions.

First we answer the question what are the optimal decision-making adjustments of OEM and TPR with the shareholding business? We show that shareholding operation always brings positive remanufactured product sales growth, but reduces the sales of new products. Besides, overall sales volume is expanded. This conclusion confirms the practical business, after cooperating with TPR, the OEM is more concerned about his profits in remanufactured product. In addition, the proportion of shares for the OEM $\lambda$ increases the sales quantity of remanufactured products but reduces the output of new products. This reflects that the OEM can influence the sales volume of the product in the market by changing the proportion of shareholding.

Second we answer the latter question whether equity participation achieves benefits for all parties in the supply chain as well as for consumer welfare? We find that besides production cost cost of holding shares will have an effect on OEM's and TPR's optimal profits. Specifically, there exists an upper boundary for the cost of holding shares, both OEM and TPR can benefit more when the equity holding cost and remanufactured cost is relatively small. This conclusion shows that OEM should not only pay attention to the balance the production cost between new and remanufactured products but also focus on investment efficiency of shareholding

Third we answer the third question what is the environmental impact of the OEM's shareholding operation on TPR's remanufacturing? Based on LCA-approach we find that when the environmental pollution associated with a remanufactured product is relatively small, the shareholding operation provides a greener solution compared with Model $N$. Conversely, if the relative remanufacturing pollution increases, the no-shareholding supply chain structure is more conducive to reducing the environmental impact. Thus, this result has practical implications for the industry. For those industries where remanufacturing causes relatively high pollution, OEM and TPR should not consider shareholding cooperation and produce independently. For those industries where remanufacturing causes relatively low pollution, shareholding operation between OEM and TPR is an effective way to reduce environment impact.

Finally under what conditions an economic and environmental win-win situation can be achieved in terms of shareholding operation? Our finding shows that when the environmental impact generated by remanufactured products and the equity holding cost is small, the shareholding operation improves consumer surplus and the economic performance of the whole supply chain, and the environment benefits.

Sincerely, we acknowledge a few limitations of the model used in this study. First, we assumed a monopoly OEM and complete information, all of which could be lessened in future research. Second, to maintain the focus on our research questions, we assumed that ownership interests had no control over the target's decision-making and pricing. Third, there is the possibility of measuring bargaining power between the OEM and TPR to dispose of this ownership problem, which could be an interesting question for future research. Finally, this study only considers the OEM's single-period decisions. Without this limitation, the results obtained may be different if two-period decisions were considered in the Stackelberg model.

\section{Appendix A. Proof}

- To accommodate space constraints, we will only provide a sketch of the proofs for some results. A detailed analysis of these results is available from the authors upon request.

- The equilibrium solutions under two models are presented in the following Table A.1. 
TABle A.1. Equilibrium decisions and profits.

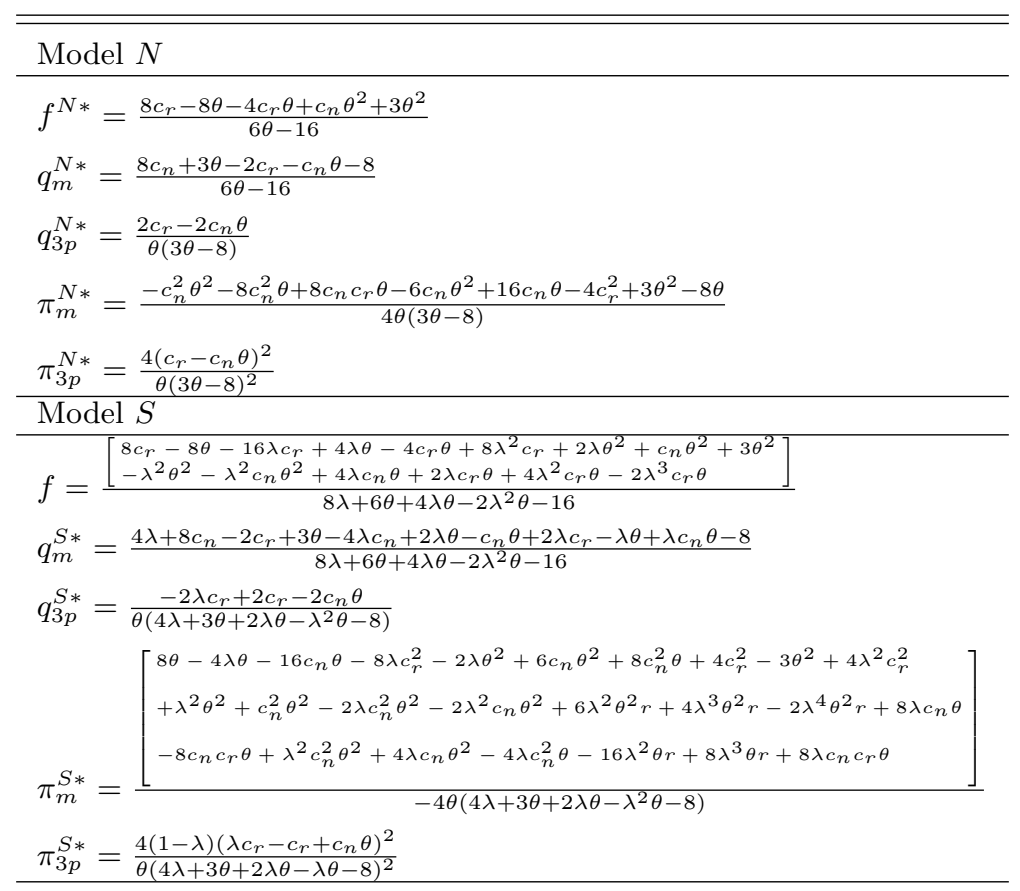

\section{A.1. Proof of Model N}

First, we can solve the following equations simultaneously, $\partial \pi_{m}^{N} / \partial q_{n}=1-2 q_{n}-\theta q_{r}-c_{n}=0$ and $\partial \pi_{3 p}^{N} / \partial q_{q}=$ $-c_{r}-f-\theta\left(q_{n}+q_{r}-1\right)-\theta q_{r}=0$. Then Plugging $q_{n}^{*}$ and $q_{r}^{*}$ into the OEM's profits and solve equations $\partial \pi_{m}^{N} / \partial f=-\left(8 c_{r}+16 f-8 \theta-4 c_{r} \theta-6 f \theta+c_{n} \theta^{2}+3 \theta^{2}\right) /\left(\theta(\theta-4)^{2}\right)=0$. At last, substituting $q_{n}^{N *}, q_{r}^{N *}$ and $f^{N *}$ in equations (4.1) and (4.2), and get the OEM's and TPR's optimal profit in Model $N$. we solve the parameter scope of these nonlinear conditions: $\Delta=\left(-8+8 c_{n}+3 \theta-c_{n} \theta\right) / 2<c_{r}<c_{n} \theta$, iff $0<\theta, c_{n}<1$.

\section{A.2. Proof of Model $S$}

First, we can solve the following equations simultaneously, $\partial \pi_{m}^{S} / \partial q_{n}=1-2 q_{n}-\theta q_{r}-\lambda \theta q_{r}-c_{n}=0$ and $\partial \pi_{3 p}^{S} / \partial q_{q}=(\lambda-1)\left(f+\theta\left(q_{n}+q_{r}-1\right)-\lambda c_{r}+c_{r}\right)=0$. Then Plugging $q_{n}^{*}$ and $q_{r}^{*}$ into the OEM's profits and solve equations $\partial \pi_{m}^{N} / \partial f=-\left(8 c_{r}+16 f-8 \theta-16 \lambda c_{r}-8 \lambda f+4 \lambda \theta-4 c_{r} \theta-6 f \theta+8 \lambda^{2} c_{r}+2 \lambda \theta^{2}+c_{n} \theta^{2}+3 \theta^{2}-\lambda^{2} \theta^{2}-\lambda^{2} c_{n} \theta^{2}+\right.$ $\left.4 \lambda c_{n} \theta+2 \lambda c_{r} \theta-4 \lambda f \theta+4 \lambda^{2} c_{r} k-2 \lambda^{3} c_{r} \theta+2 \lambda^{2} f \theta\right) /\left(\theta(\theta+\lambda \theta-4)^{2}\right)=0$. At last, substituting $q_{n}^{S *}, q_{r}^{S *}$ and $f^{S *}$ in equations (4.1) and (4.2), and get the OEM's and TPR's optimal profit in Model $S$. we solve the parameter scope of these nonlinear conditions: $\left.\Delta^{S}=\left(4 \lambda+8 c_{n}+3 \theta-4 \lambda c_{n}+2 \lambda \theta-c_{n} \theta-\lambda^{2} \theta+\lambda^{2} c_{n} \theta-8\right) /\left(2-2 \lambda^{2}\right)\right)<$ $c_{r}<c_{n} \theta /(1-\lambda)$, and $\bar{r}=-\left(c_{n}^{2} \theta\right) /(2 \lambda(2 \lambda+2 \theta-\lambda \theta-3))$, iff $0<\theta, c_{n}<1$ and $0<\lambda<1 / 2$.

Then, we compare the range of the threshold $\Delta^{N}$ and the threshold $\Delta^{S}$, and make sure the comparative range is: $\Delta=\underline{c}_{r}<c_{r}<\bar{c}_{r}$, where $\bar{c}_{r}=c_{n} \theta$ and $\left.\underline{c}_{r}=\left(4 \lambda+8 c_{n}+3 \theta-4 \lambda c_{n}+2 \lambda \theta-c_{n} \theta-\lambda^{2} \theta+\lambda^{2} c_{n} \theta-8\right) /(2-2 \lambda)^{2}\right)$. In the range of the threshold $\Delta$, we compare the equilibrium solution between Model $N$ and Model $S$.

\section{A.3. Proof of Proposition 5.1}

To prove $f^{S *}>f^{N *}$, we let $f^{S *}-f^{N *}=0$ and the first derivative is $\partial\left(f^{S *}-f^{N *}\right) / \partial c_{r}>0$. Thus, we obtain the threshold point $c_{r_{1}}=\left(c_{n} \theta\left(\lambda \theta^{2}-4 \lambda \theta-4 \theta+\theta^{2}+16\right)\right) /\left(-3 \lambda^{2} \theta^{2}+8 \lambda^{2} \theta+4 \lambda \theta^{2}-32 \lambda+7 \theta^{2}-32 \theta+48\right)$. It is easy to calculate that $c_{r_{1}}<\bar{c}_{r}$, while there exists a threshold $c_{n_{1}}=\left(-48+32 \lambda+32 \theta-8 \lambda^{2} \theta-7 \theta^{2}-4 \lambda \theta^{2}+\right.$ 
$\left.3 \lambda^{2} \theta^{2}\right) /\left(-48+32 \lambda+24 \theta-8 \lambda \theta-8 \lambda^{2} \theta-3 \theta^{2}+3 \lambda^{2} \theta^{2}\right)$, iff $c_{n}<c_{n_{1}}, \underline{c}_{r}<c_{r_{1}}<\bar{c}_{r}$. Iff $c_{n}>c_{n_{1}}, c_{r_{1}}<\underline{c}_{r}$. That is to say, when $c_{n}<c_{n_{1}}$ and $c_{r}<c_{r_{1}}, f^{S *}<f^{N *}$. When $c_{n}<c_{n_{1}}$ and $c_{r}>c_{r_{1}}$ or $c_{n}>c_{n_{1}}, f^{S *}>f^{N *}$ always hold.

\section{A.4. Proof of Proposition 5.2}

To prove $q_{r}^{S *}>q_{r}^{N *}$, we let $q_{r}^{S *}-q_{r}^{N *}=0$ and the first derivative is $\partial\left(q_{r}^{S *}-q_{r}^{N *}\right) / \partial c_{r}>0$. Thus, we obtain the threshold point $c_{r a}=c_{n} \theta(12-\theta-\lambda \theta) /(2 \theta-8 \lambda+2 \lambda \theta+4)$, It is easy to obtain $c_{r a}>\bar{c}_{r}$, thus $q_{r}^{S *}>q_{r}^{N *}$. Applying a computational process similar to the previous one, we obtain $q_{n}^{S *}<q_{n}^{N *}$ and $q_{n}^{S *}+q_{r}^{S *}>q_{n}^{N *}+q_{r}^{N *}$.

\section{A.5. Proof of Proposition 5.3}

To prove $\pi_{m}^{S *}>\pi_{m}^{N *}$, we let $\pi_{m}^{S *}-\pi_{m}^{N *}=0$ and we obtain the threshold point $r_{1}=\left(16 \lambda c_{r}^{2}+16 c_{r}^{2} \theta-24 c_{r}^{2}+\right.$ $\left.8 c n^{2} \theta^{2}+4 c_{n}^{2} \theta^{3}-2 \lambda c_{n}^{2} \theta^{3}+16 c_{n} c_{r} \theta-8 \lambda c_{r}^{2} \theta-20 c_{n} c_{r} \theta^{2}+4 \lambda c_{n} c_{r} \theta^{2}\right) /\left(\lambda \theta(3 \theta-8)\left(4 \lambda+3 \theta+2 \lambda \theta-\lambda^{2} \theta-8\right)\right)$. It is easy to obtain $r_{1}<\bar{r}$. We let $r_{1}=0$, and thus we obtain two intersection point $c_{r b}>\bar{c}_{r}$ and $c_{r c}<\underline{c}_{r}$. We calculate the second derivative $\partial^{2} r_{1} / \partial^{2} c_{r}<0$, thus when $\underline{c}_{r}<c_{r}<\bar{c}_{r}, r_{1}>0$ always hold. We calculate the first derivative $\partial\left(\pi_{m}^{S *}-\pi_{m}^{N *}\right) / \partial r<0$. Thus when $r<r_{1}, \pi_{m}^{S^{*}}>\pi_{m}^{N *}$, when $r_{1}<r<\bar{r}, \pi_{m}^{S *}<\pi_{m}^{N *}$.

\section{A.6. Proof of Proposition 5.4}

To prove $\pi_{3 p}^{S *}>\pi_{3 p}^{N *}$, we let $\pi_{3 p}^{S *}-\pi_{3 p}^{N *}=0$ and we obtain two intersection point $c_{r d}>\bar{c}_{r}$ and $\underline{c}_{r}<c_{r_{2}}=$ $-\left(c_{n} \theta\left(48 \lambda-80 \lambda \theta-\left(32 \lambda+48 \theta-64-9 \theta^{2}-6 \lambda \theta^{2}-8 \lambda^{2} \theta+3 \lambda^{2} \theta^{2}+4 \lambda \theta\right) \sqrt{1-\lambda}+104 \theta+11 \lambda \theta^{2}+8 \lambda^{2} \theta-30 \theta^{2}+\right.\right.$ $\left.\left.4 \lambda^{2} \theta^{2}-\lambda^{3} \theta^{2}-64\right)\right) /\left(\lambda^{3} \theta^{2}+5 a^{2} \theta^{2}-56 \lambda^{2} \theta+64 \lambda^{2}-29 \lambda \theta^{2}+176 \lambda \theta-176 \lambda+39 \theta^{2}-152 \theta+128\right)<\bar{c}_{r}$. We calculate the second derivative $\partial\left(\pi_{3 p}^{S *}-\pi_{3 p}^{N *}\right) / \partial c_{r}>0$, thus when $c_{r}<c_{r_{2}}, \pi_{3 p}^{S *}<\pi_{3 p}^{N *}$ always hold. When $c_{r}>c_{r_{2}}$, $\pi_{3 p}^{S *}>\pi_{3 p}^{N *}$.

\section{A.7. Proof of Proposition 5.5}

To prove $\Pi^{S *}>\Pi^{N *}$, we let $\Pi^{S *}-\Pi^{N *}=0$ and we obtain the threshold point $r_{2}$, applying a computational process similar to the proof of Proposition 5.3, it is easy to obtain $0<r_{2}<r_{1}<\bar{r}$ always hold. We calculate the first derivative $\partial\left(\Pi^{S *}-\Pi^{N *}\right) / \partial r<0$. Thus, when $r_{2}<r<r_{1}, \Pi^{S *}<\Pi^{N *}$, when $0<r<r_{2}, \Pi^{S *}>\Pi^{N *}$.

\section{A.8. Proof of Proposition 5.6}

To compare the total environment impacts between Model $S$ and Model $N$, we let $E^{S}-E^{N}=\left(\lambda\left(8 c_{r} e_{2}+\right.\right.$ $8 c_{n} e_{2} \theta+4 c_{r} e_{1} \theta-10 c_{r} e_{2} \theta-12 c_{n} e_{1} \theta^{2}+c_{n} e_{1} \theta^{3}+4 c_{n} e_{2} \theta^{2}+2 c_{r} e_{1} \theta^{2}+\lambda c_{n} e_{1} \theta^{3}-2 \lambda c_{n} e_{2} \theta^{2}+2 \lambda c_{r} e_{1} \theta^{2}-8 \lambda c_{r} e_{1} \theta+$ $\left.\left.2 \lambda c_{r} e_{2} \theta\right)\right) /\left(\theta(3 \theta-8)\left(4 \lambda+3 \theta+2 \lambda \theta-\lambda^{2} \theta-8\right)\right)=0$ and we obtain the threshold point $e_{2}=-\theta e_{1}\left(4 c_{r}-8 \lambda c_{r}-\right.$ $\left.12 c_{n} \theta+2 c_{r} \theta+c_{n} \theta^{2}+2 \lambda c_{r} \theta+\lambda c_{n} \theta^{2}\right) / 2\left(4 c_{r}+4 c_{n} \theta-5 c_{r} \theta+2 c_{n} \theta^{2}+\lambda c_{r} \theta-\lambda c_{n} \theta^{2}\right)$, we let $I=e_{2} / e_{1}$ and it is easy to obtain $0<I<1$. We calculate the first derivative $\partial\left(E^{S}-E^{N}\right) / \partial e_{2}>0$, thus, when $0<e_{2} / e_{1}<I$, $E^{S}<E^{N}$, when $I<e_{2} / e_{1}<1, E^{S}>E^{N}$.

\section{A.9. Proof of Corollary 5.7}

To prove $\mathrm{CS}^{S}>\mathrm{CS}^{N}$, we let $\mathrm{CS}^{S}-\mathrm{CS}^{N}=0$ and we obtain two intersection point $c_{r e}>\bar{c}_{r}$ and $c_{r f}<\underline{c}_{r}$. We calculate the second derivative $\partial^{2} r_{1} / \partial^{2} c_{r}<0$, thus when $\underline{c}_{r}<c_{r}<\bar{c}_{r}, \mathrm{CS}^{S}>\mathrm{CS}^{N}$ always hold.

\section{A.10. Proof of Corollary 5.8}

We calculate the first-order condition of the pollution ratio I under this condition with respect to $c_{r}$. That is $\partial I / \partial c_{r}=c_{n} \theta^{2}(8-3 \theta)\left(4 \lambda+3 \theta+2 \lambda \theta-\lambda^{2} \theta-8\right) /\left(2\left(4 c_{r}+4 c_{n} \theta-5 c_{r} \theta+2 c_{n} \theta^{2}+\lambda c_{r} \theta-\lambda c_{n} \theta^{2}\right)^{2}\right)$. It is easy to obtain the denominator is always greater than 0 , and the molecule is always less than 0 . That is to say, $\partial I / \partial c_{r}<0$ always hold. Applying a computational process similar to the previous one, we get $\partial I / \partial c_{n}>0$, $\partial I / \partial \lambda>0$ and $\partial I / \partial \theta>0$. 
Acknowledgements. The authors thank the National Natural Science Foundation of China under Grant (71872028) and Grant (71472026), Research Fund for the Circular Economy (XHJJ-1801 and XHJJ-1805) for supporting this research. The authors have declared that no competing interests exist.

Data availability statement. All Data is in this paper.

\section{REFERENCES}

[1] V. Agrawal, A. Atasu, K. Van Ittersum, Remanufacturing, third-party competition, and consumers' perceived value of new products. Manage. Sci. 61 (2015) 60-72.

[2] A. Atasu and G.C. Souza, How does product recovery affect quality choice? Prod. Oper. Manage. 22 (2013) 991-1010.

[3] A. Atasu, L.N. Van Wassenhove and M. Sarvary, Efficient take-back legislation. Prod. Oper. Manage. 18 (2019) $243-258$.

[4] D. Basak, Cournot vs. Bertrand under centralised bargaining. Econ. Lett. 154 (2017) 124-127.

[5] M. Becker-Peth and U.W. Thonemann, Reference points in revenue sharing contracts - How to design optimal supply chain contracts. Eur. J. Oper. Res. 249 (2016) 1033-1049.

[6] V. Blass, Closed-loop supply chains: new developments to improve the sustainability of business practices, edited by Mark E. Ferguson and Gilvan C. Souza. J. Ind. Ecol. 16 (2012) 285-285.

[7] D. Brito, L. Cabral and H. Vasconcelos, Divesting ownership in a rival. Int. J. Ind. Organ. 34 (2014) 9-24.

[8] G.P. Cachon and M.A. Lariviere, Supply chain coordination with revenue-sharing contracts: strengths and limitations. Manage. Sci. 51 (2005) 30-44.

[9] J. Cao, X. Chen, X. Zhang, Y. Gao, X. Zhang and S. Kumar, Overview of remanufacturing industry in China: government policies, enterprise, and public awareness. J. Clean. Prod. 242 (2020) 118450.

[10] S.S. Chauhan and J.M. Proth, Analysis of a supply chain partnership with revenue sharing. Int. J. Prod. Econ. 97 (2005) $44-51$.

[11] J. Chen, Q. Hu and J.S. Song, Effect of partial cross ownership on supply chain performance. Eur. J. Oper. Res. 258 (2017) $525-536$.

[12] S. Dasgupta and Z. Tao, Bargaining, bonding, and partial ownership. Int. Econ. Rev. 41 (2000) 609-635.

[13] G. Esenduran, E. Kemahlığlu-Ziya, J.M. Swaminathan, Take-back legislation: consequences for remanufacturing and environment. Decision. Sci. 47 (2016) 219-256.

[14] G. Esenduran, E. Kemahlığlu-Ziya and J.M. Swaminathan, Impact of take-back regulation on the remanufacturing industry. Prod. Oper. Manage. 26 (2017) 924-944.

[15] C. Fang, Z. You, Y. Yang, D. Chen and S. Mukhopadhyay, Is third-party remanufacturing necessarily harmful to the original equipment manufacturer? Ann. Oper. Res. (2019) 1-22.

[16] M.E. Ferguson and L.B. Toktay, The effect of competition on recovery strategies. Prod. Oper. Manage. 15 (2006) $351-368$.

[17] H. Fu and Y. Ma, Optimization and coordination of decentralized supply chains with vertical cross-shareholding. Comput. Ind. Eng. 132 (2019) 23-35.

[18] X. Gao and H. Zheng, Environmental concerns, environmental policy and green investment. Int. J. Env. Res. Pub. He. 14 (2017) 1570.

[19] R. Geyer, L.N. Van Wassenhove and A. Atasu, The economics of remanufacturing under limited component durability and finite product life cycles. Manage. Sci. 53 (2007) 88-100.

[20] A. Ghosh and H. Morita, Knowledge transfer and partial equity ownership. Rand. J. Econ. 48 (2017) $1044-1067$.

[21] B. Gomes, Do alliances promote knowledge flows? J. Financ. Econ. 80 (2006) 5-33.

[22] K. Govindan, L.P. Feng and C.F. Li, Strategic planning: design and coordination for dual-recycling channel reverse supply chain considering consumer behavior. Eur. J. Oper. Res. 260 (2017) 601-612.

[23] P. Greenlee and A. Raskovich, Partial vertical ownership. Eur. Econ. Rev. 50 (2006) 1017-1041.

[24] W. Gu, D. Chhajed, N.C. Petruzzi and B. Yalabik, Quality design and environmental implications of green consumerism in remanufacturing. Int. J. Prod. Econ. 162 (2015) 55-69.

[25] T.G. Gutowski, S. Sahni, A. Boustani and S.C. Graves, Remanufacturing and energy savings. Environ. Sci. Technol. 45 (2011) $4540-4547$.

[26] Q.D. He, N.M. Wang, Z. Yang, Z.W. He and B. Jiang, Competitive collection under channel inconvenience in closed-loop supply chain. Eur. J. Oper. Res. 275 (2019) 155-166.

[27] F. Höffler and S. Kranz, Legal unbundling can be a golden mean between vertical integration and ownership separation. Int. J. Ind. Organ. 29 (2011) 576-588.

[28] F.U. Hong, M.A. Yongkai and C.A.I. Xiaoqiang, Downstream firm's investment with equity holding in decentralized assembly systems. Omega-Int. J. Manage. S. 75 (2018) $27-56$.

[29] B. Hu, D. Xu and C. Meng, Inconsistency of a retailer's optimal policies and channel performance under revenue sharing contracts. Int. J. Prod. Econ. 183 (2017) 53-65.

[30] M. Hunold and K. Stahl, Passive vertical integration and strategic delegation. Rand. J. Econ. 47 (2016) 891-913.

[31] M. Jin, J. Nie, F. Yang and Y. Zhou, The impact of third-party remanufacturing on the forward supply chain: a blessing or a curse? Int. J. Prod. Res. 55 (2017) 6871-6882. 
[32] I. Karakayali, H. Emir-Farinas and E. Akcali, An analysis of decentralized collection and processing of end-of-life products. J. Oper. Manage. 25 (2007) 1161-1183.

[33] A. Kumar, R.B. Chinnam and A. Murat, Hazard rate models for core return modeling in auto parts remanufacturing. Int. J. Prod. Econ. 183 (2017) 354-361.

[34] Y.C. Lee, Y.C. Hsiao, C.F. Peng, S.B. Tsai, C.H. Wu and Q. Chen, Using mahalanobis-taguchi system, logistic regression and neural network method to evaluate purchasing audit quality. Proc. Inst. Mech. Eng. Part B: J. Eng. Manuf. 229 (2014) 3-12.

[35] T. Levitt, Exploit the product life cycle. Harvard Bus. Rev. 43 (1965) 81-94.

[36] N. Levy, Y. Spiegel and D. Gilo, Partial vertical integration, ownership structure, and foreclosure. Am. Econ. J. Microecon. 10 (2018) 132-180.

[37] G.D. Li, M. Reimann and W.H. Zhang, When remanufacturing meets product quality improvement: the impact of production cost. Eur. J. Oper. Res. 271 (2018) 913-925.

[38] W. Liu, H.B. Shi, Z. Zhang, S.B. Tsai, Y. Zhai, Q. Chen and J. Wang, The development evaluation of economic zones in China. Int. J. Environ. Res. Publ. Health 15 (2018) 56.

[39] Z. Liu, K.W. Li, B.Y. Li, J. Huang and J. Tang, Impact of product-design strategies on the operations of a closed-loop supply chain. Transp. Res. E-log. 124 (2019) 75-91.

[40] Z.J. Ma, Z. Qin, D. Ying and J.B. Sheu, Optimal pricing decisions under the coexistence of "trade old for new" and "trade old for remanufactured" programs. Transp. Res. E-log. 106 (2017) 337-352.

[41] H.T. Normann, W. Güth and N. Nikiforakis, Vertical cross-shareholding: theory and experimental evidence. Int. J. Ind. Organ. 25 (2007) 69-89.

[42] A. Örsdemir, E. Kemahlığlu-Ziya and A.K. Parlaktürk, Competitive quality choice and remanufacturing. Prod. Oper. Manage. 23 (2014) 48-64.

[43] A. Ovchinnikov, V. Blass and G. Raz, Economic and environmental assessment of remanufacturing strategies for product+ service firms. Prod. Oper. Manage. 23 (2014) 744-761.

[44] Z. Qian, J. Chai, H. Li, W. Yan and H. Chen, Implications of product upgrading confronting supplier remanufacturing. Int. J. Prod. Res. (2019) 1-23.

[45] J. Quariguasi-Frota-Neto and J. Bloemhof, An analysis of the Eco-Efficiency of remanufactured personal computers and mobile phones. Prod. Oper. Manage. 21 (2012) 101-114.

[46] D. Reitman, Partial ownership arrangements and the potential for collusion. J. Ind. Econ. 42 (1994) 313-322.

[47] D.R. Rink and J.E. Swan, Product life cycle research: a literature review. J. Bus. Res. 7 (1979) 219-242.

[48] S. Shelegia and Y. Spiegel, Bertrand competition when firms hold passive ownership stakes in one another. Econ. Lett. 114 (2012) 136-138.

[49] J.J. Spengler, Vertical integration and antitrust policy. Eur. J. Polit. Econ. 58 (1950) 347-352.

[50] Z. Tao, S.X. Zhou and C.S. Tang, Managing a remanufacturing system with random yield: properties, observations, and heuristics. Prod. Oper. Manage. 21 (2012) 797-813.

[51] S.-B. Tsai, Y.-C. Lee, C.-H. Wu, J.-J. Guo, Examining how manufacturing corporations win orders. S. Afr. J. Ind. Eng. 24 (2013) 112-124.

[52] S.B. Tsai, J. Yu, L. Ma, F. Luo, J. Zhou, Q. Chen and L. Xu, A study on solving the production process problems of the photovoltaic cell industry. Renew. Sustainable Energy Rev. 82 (2018) 3546-3553.

[53] L. Wang and M. Chen, Policies and perspective on end-of-life vehicles in China. J. Clean. Prod. 44 (2013) 168-176.

[54] X. Wu and Z. Yu, Does the entry of third-party remanufacturers always hurt original equipment manufacturers? Decision. Sci. 47 (2016) 762-780.

[55] X. Wu and Y. Zhou, The optimal reverse channel choice under supply chain competition. Eur. J. Oper. Res. 2592017 63-66.

[56] W. Yan, Y. Xiong, Z. Xiong and N. Guo, Bricks vs. clicks: Which is better for marketing remanufactured products? Eur. J. Oper. Res. 242 (2015) 434-444.

[57] W. Yan, H. Li, J. Chai, Z. Qian and H. Chen, Owning or outsourcing? Strategic choice on take-back operations for third-party remanufacturing. Sustainability 10 (2018) 151.

[58] A. Yenipazarli, Managing new and remanufactured products to mitigate environmental damage under emissions regulation. Eur. J. Oper. Res. 249 (2016) 117-130.

[59] M.-C. Yu, Q. Mai, S.B. Tsai, Y. Dai, An empirical study on the organizational trust, employee-organization relationship and innovative behavior from the integrated perspective of social exchange and organizational sustainability. Sustainability 10 (2018) 864.

[60] L. Zhi, J. Tang, B. Li and W. Zhe, Trade-off between remanufacturing and recycling of WEEE and the environmental implication under the Chinese Fund Policy. J. Clean. Prod. 167 (2017) 97-109.

[61] J. Zhou, Q. Wang, S.-B. Tsai, Y. Xue and W. Dong, How to evaluate the job satisfaction of development personnel. IEEE Trans. Syst. Man Cybern.-Syst. 47 (2017) 2809-2816.

[62] X. Zhu, Z. Wang, Y. Wang and B. Li, Incentive policy options for product remanufacturing: subsidizing donations or resales? Int. J. Env. Res. Pub. He. 14 (2017) 1496.

[63] Z.B. Zou, J.J. Wang, G.S. Deng and H. Chen, Third-party remanufacturing mode selection: outsourcing or authorization? Transp. Res. E-log. 87 (2016) 1-19. 